\title{
Evaluation of a sulfanilic acid based surfactant in crude oil demulsification: an experimental study
}

\author{
Ghassem Zargar $^{1}$, Reza Ghol Gheysari ${ }^{1}$, Mohammad Ali Takassi ${ }^{2}$, Alireza Rostami ${ }^{1,}{ }^{*}$, and Amin Zadehnazari ${ }^{2}$ \\ 1 Department of Petroleum Engineering, Petroleum University of Technology (PUT), Ahwaz - Iran \\ ${ }^{2}$ Department of Science, Petroleum University of Technology, Ahwaz - Iran
}

Received: 9 January 2018 / Accepted: 23 April 2018

\begin{abstract}
In this study, 2-Amino-5-Dodecyl Benzene Sulfonic Acid (ADBSA) surfactant has been prepared and tested as crude oil emulsions demulsifier. Electrical conductivity method was used to obtain the critical micelle concentration of surfactant. A critical micelle concentration value of $0.225 \mathrm{wt} . \%$. Bottle testing measurements were conducted to investigate the effect of several parameters including temperature, water content, salinity, demulsifier dosage and type of crude oil (composition) on the demulsification efficiency in presence of new synthetic demulsifier. A reduction of emulsion stability was observed with increasing water content or demulsifier dosage decrease. A water separation index of $98 \%$ was recorded at $60^{\circ} \mathrm{C}$.
\end{abstract}

\section{Introduction}

Presence of water in crude oil as emulsions is a common subject in crude oil processing. The origins of formation of these emulsions are the shear and other restrictions created by the pumping of water-crude oil mixture through the valves, elbows and pipes. Water-in-Oil (W/O) emulsions are stabilized by asphaltenes and other natural occurring surfactants in crude oil [1-3]. Emulsion may be defined as a highly stable dispersion of droplets of a liquid with a certain size in a second immiscible liquid [4,5]. This emulsion causes many problems for petroleum industry. These problems include increased oil viscosity, associated corrosion problems, extra-expense of transportation, poisoning of downstream refinery catalysts, and required additional production equipment $[6,7]$. As a result, separation of this water from crude oil is very important in process operation [8-10].

Demulsification is the process of breaking emulsions with the aim of separating water from crude oil [11]. Emulsion-treating technologies are carried out when storage tanks cannot remove $\mathrm{W} / \mathrm{O}$ emulsion [12]. There are several research studies in the open literature concerning the demulsification process and evaluation of the $\mathrm{W} / \mathrm{O}$ emulsion [13-18].

There are two main demulsification methods: physical and chemical [19]. Some physical demulsification methods include supersonic demulsification [20], microwave radia-

\footnotetext{
* Corresponding author:

alireza.rostami . put2014@gmail.com
}

tion [21-24], centrifugation [25], and electro-sedimentation $[26,27]$. In chemical demulsification, demulsifiers are applied to extend the surface area at the water-crude oil interfaces and breaking the firm film around water droplets in order to separate water from oil $[28,29]$.

The main goal of this article is study the impact of different parameters in presence of the new demulsifier. In present study 2-Amino-5-Dodecyl Benzene Sulfonic Acid (ADBSA) an amphoteric surfactant was prepared [30]. The demulsification properties of this surfactant were studied in detail. synthetic brine in crude oil emulsions were used in bottle testing at different temperature, demulsifier concentration, water content, oil properties and water salinity $[31,32]$.

\section{Experimental}

\subsection{Materials}

Anhydrous aluminum chloride $\left(\mathrm{AlCl}_{3}\right)$, acetonitrile, acetic anhydride, 1-bromododecane (dodecyl bromide), 2-Aminobenzenesulfonic acid, sodium hydroxide and hydrochloric acid were used as received without further purification. These chemicals were purchased from Merck Chemical Co. (Germany) and Aldrich Chemical Co. (Milwaukee, WI), USA.

\subsection{Surfactant}

2-Amino-5-Dodecyl Benzene Sulfonic Acid (ADBSA) an amphoteric surfactant was prepared with $85 \%$ yield. The following procedure was used in the synthesis of ADBSA 


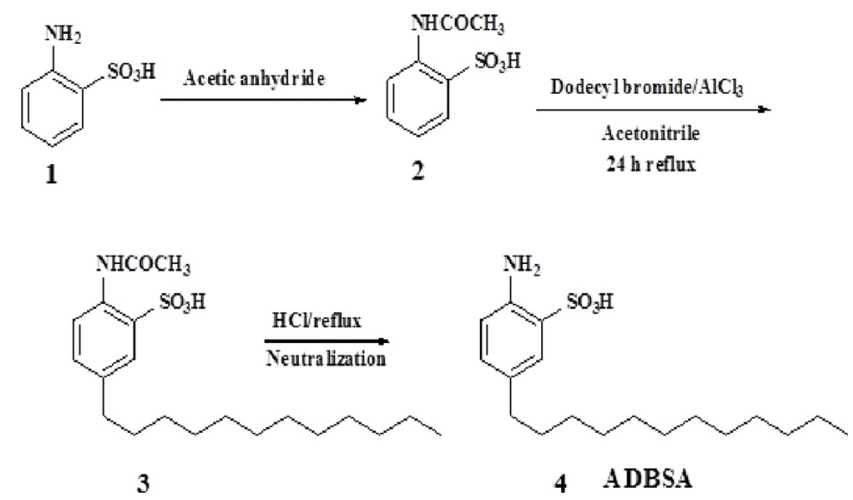

Fig. 1. Synthetic route of the target ADBSA surfactant.

surfactant. $1.00 \mathrm{~g}$ of ortho-sulfanilic acid was placed in $50 \mathrm{~mL}$ 6.0 M hydrochloric acid and stirred using magnetic stirrer for $30 \mathrm{~min}$ some remained in the solution (container A). Then $8 \mathrm{~mL}$ of acetic anhydride was added to container A; at this time the remained ortho-sulfanilic acid was dissolved and a clear solution was obtained. In container B, $18.00 \mathrm{~g}$ of sodium acetate was dissolved in $35.0 \mathrm{~mL}$ of distilled water. Container B was placed in an ice water bath; then the solution from container A was added to container B and stirred for $4 \mathrm{~h}$. At this time the container B was heated gently to evaporate water; when the volume of solution reduced to half, a greenish white precipitate formed; to complete precipitation it was placed in ice water bath for $24 \mathrm{~h}$, it was filtered and washed then air dried (compound 2). In the next step, compound 2 was placed in a round bottom flask along with $0.10 \mathrm{~g}$ anhydrous aluminum chloride, $100.0 \mathrm{~mL}$ acetonitrile while it was stirring $2.0 \mathrm{~mL}$ dodecyl bromide was added slowly drop wise. After the addition was completed, the stirring was continued at reflux temperature for an additional $24 \mathrm{~h}$. The flask was cooled and a white precipitate (compound 3) was formed; the acetonitrile was decanted; at this time $30.0 \mathrm{~mL}$ of $6.0 \mathrm{M}$ hydrochloric acid was added to the flask and heated under reflux; compound 3 was dissolved and a clear solution was obtained. The flask was cooled to room temperature. $3.0 \mathrm{M}$ sodium hydroxide solution was added to neutralize the acid, when neutralization was complete the solution turn cloudy. Finally, the flask was placed in an ice water bath a white precipitate was formed (compound 4), it was filtered and air dried. Compound 4 was recrystallized in ethanol. The synthetic pathway leading to the synthesis of target ADBSA surfactant is demonstrated in Figure 1.

\subsection{Crude oil}

The crude oils used in this study were dead oil samples from Iranian south oil reservoirs including Asmari (P1), Binak (P2) and Azadegan (P3).

\subsection{Synthetic brine}

A certain amount of $\mathrm{NaCl}$ was dissolved in sufficient distilled water to prepare brine. The details of the process will be explained in subsequent sections.

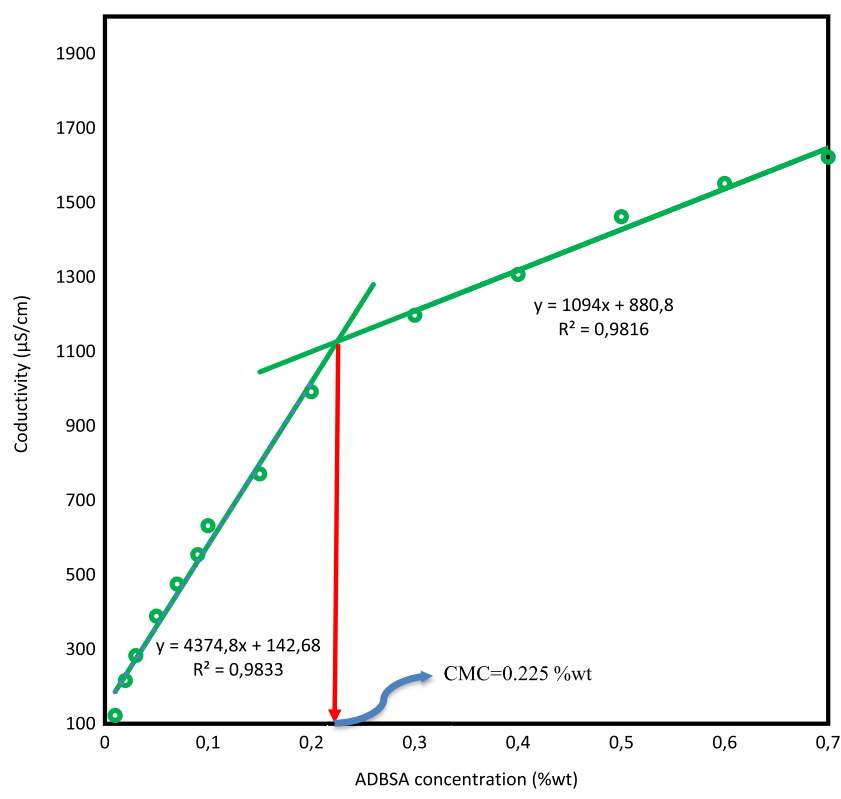

Fig. 2. Conductivity of surfactant solution versus concentration to determine ADBSA CMC.

\section{Methods}

\subsection{CMC measurement}

The electrical conductivity technique was used to determine the Critical Micelle Concentration (CMC) of the surfactant. Jenway- 4510 conductivity apparatus was used in these experiments. The conductivity of solutions was plotted versus surfactant concentrations; two distinct trend lines were observed. The CMC value corresponds to the point where a variation in the rate of conductivity occurs. Figure 2 exhibits the plot of solutions conductivity versus surfactant concentration at $25^{\circ} \mathrm{C}$. The $\mathrm{CMC}$ value of ADBSA surfactant is $0.225 \mathrm{wt} . \%$.

\subsection{Preparation of water in crude oil emulsion}

The demulsification tests were carried out using synthetic $\mathrm{W} / \mathrm{O}$ emulsion. These emulsions were synthesized from mixing crude oil and brine. The aqueous phase is a $\mathrm{NaCl}$ solution. Appropriate volume of emulsion was prepared by shaking the fluids (oil phase and brine) in a JB-12KD (Zhengyuan Tongda Ltd.) homogenizer at $10000 \mathrm{rpm}$ for $20 \mathrm{~min}$. For example, $200 \mathrm{~mL}$ of an emulsion that contains $40 \%$ brine of $1 \mathrm{wt} . \%$ of $\mathrm{NaCl}$ was prepared as below:

$-0.8 \mathrm{~g}$ of $\mathrm{NaCl}$ was weighted and was poured in $80 \mathrm{~mL}$ of distilled water and was stirred by a magnetic stirrer until salt dissolved completely. This makes 1 wt.\% brine;

- $120 \mathrm{~mL}$ of dead oil was added into the beaker containing brine that was made previously;

- brine must disperse in oil phase. For this purpose, a powerful shear stress is necessary. Homogenizer inserts this shear stress by stirring the emulsion with $10000 \mathrm{rpm}$ and makes stable $\mathrm{W} / \mathrm{O}$ emulsion that contains $40 \% \mathrm{v} / \mathrm{v}$ brine. 
Table 1. Results from bottle testing using demulsifier at 40 and $60{ }^{\circ} \mathrm{C}$ for $30 \% \mathrm{~W} / \mathrm{O}$ emulsions.

\begin{tabular}{llllll}
\hline Temperature $\left({ }^{\circ} \mathrm{C}\right)$ & Demulsifier & Settling time $(\mathrm{min})$ & WSI $(\%)$ & Rag layer & Water quality \\
\hline \multirow{2}{*}{40} & ADBSA & 50 & 86 & None & Excellent \\
& CD & 30 & 90 & Yes & Good \\
60 & ADBSA & 30 & 95 & None & Excellent \\
& CD & 25 & 97 & Yes & Good \\
\hline
\end{tabular}

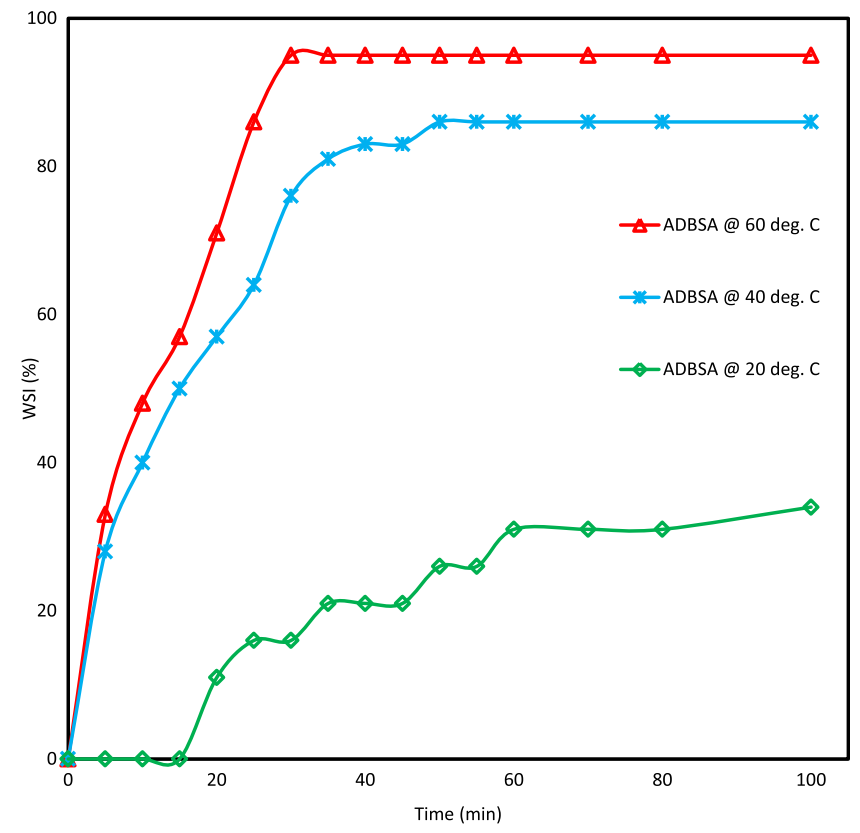

Fig. 3. Effect of temperature on demulsification efficiency of ADBSA.

These emulsions are very stable within the experimental time frame and no water separation was observed for several days. At last, the emulsion demulsification was evaluated by bottle tests.

\subsection{Bottle test}

In this section, bottle testing was implemented in order to evaluate demulsification efficiency of ADBSA surfactant. The bottle test involves, shaking the content of the container to disperse the demulsifier in the emulsions and observing the phase separation (water separation) as a function of time. Figure 3 shows a typical bottle test that was carried out in this thesis. In each test, the labeled $25 \mathrm{~mL}$ graduated cylinder was filled with freshly prepared emulsion samples up to the $25 \mathrm{~mL}$ mark. About $0.5 \mathrm{~mL}$ of the demulsifier was added to the first test tube. Thereafter, $1,1.5-3.5 \mathrm{~mL}$ was added sequentially into the remaining test tubes depend on which parameter was being studied. In most experiments, $2 \mathrm{~mL}$ of demulsifier was added to the emulsion. Then, the test tubes were shaken vigorously for $2 \mathrm{~min}$ by an electrical Orbital Shaker OS21 (Philip Harris Ltd.). At this time, the mixture was put in a water bath under desired temperatures (40 and $60^{\circ} \mathrm{C}$ ). The volume of the separated water was measured every $5 \mathrm{~min}$ for a period of $2 \mathrm{~h}$.

The demulsification performance is evaluated by the percent of Water Separation Index (WSI\%), which can be calculated from Equation (1), as below:

$$
\mathrm{WSI}=\left[\frac{\Sigma(\mathrm{SW})}{N}\right] \times 100
$$

where $\mathrm{N}$ and SW are the number of measures of separated water and separated water (\%) in a specific concentration/ time, respectively. WSI is a simple and efficient index to demonstrate the efficiency of surfactants demulsification ability.

There are different criteria for evaluation of demulsification efficiency. In addition to WSI, as a simple and efficient index to demonstrate the efficiency of surfactants demulsification ability, other criteria such as separated water quality, settling time and presence of rag layer have been studied. Quality of separated water is related to the presence of oil droplets in separated phase which is not desirable due to environmental issues and wasting oil. Another parameter is settling time defined as the time span where the highest water separation takes place. Moreover, a gel-like emulsion that forms at the interface of the oil and water in a separation vessel is called the rag layer. Presence of rag layer and separated water quality are qualitative parameters, even though settling time and WSI are quantitative ones in demulsification process. Table 1 shows a summary of bottle test results of the ADBSA and CD demulsifiers. Demulsification was carried out in the following way: $2 \mathrm{~mL}$ of demulsifier was added to $25 \mathrm{~mL}$ crude oil emulsion containing $30 \%$ brine at the selected temperature $\left(40\right.$ and $\left.60^{\circ} \mathrm{C}\right)$. The demulsification performance was improved at elevated temperature. Several factors may affect the demulsification efficiency are studied in subsequent sections. The effect water content, demulsifier dosage, brine salinity and temperature are investigated by means of Asmari oil.

\section{Results and discussions}

In this section, the effect of different parameters such as surfactant concentration, temperature, water content, emulsion stability, brine salinity and different crude oil properties are studied. 


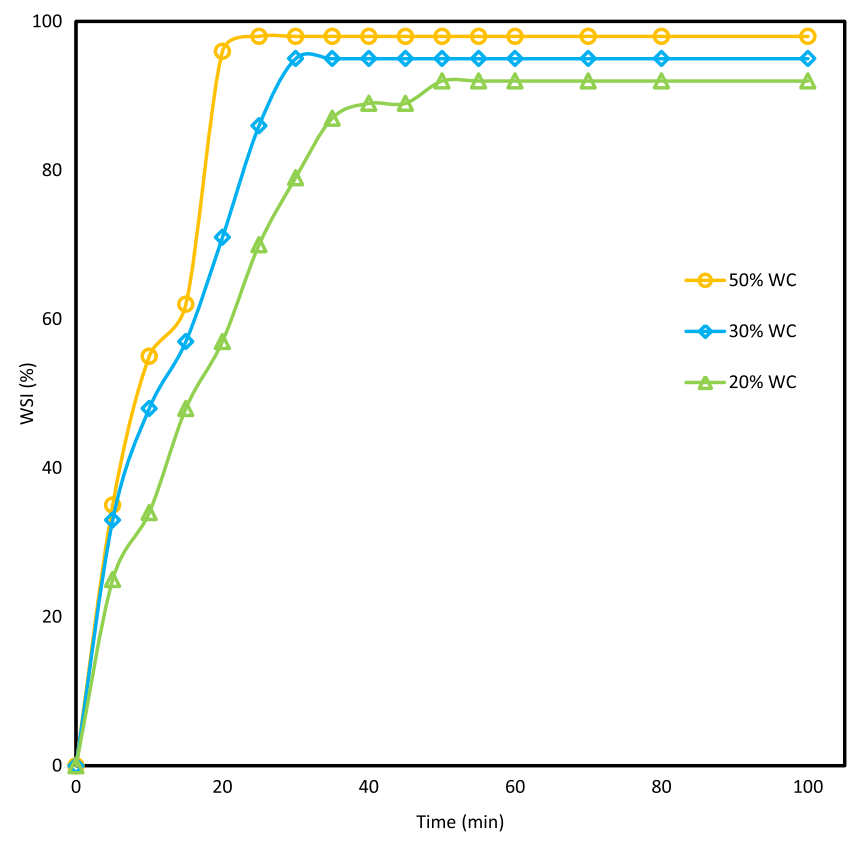

Fig. 4. Effect of emulsion water content on demulsification efficiency of ADBSA surfactant.

\subsection{Effect of temperature}

Figure 3 illustrates WSI versus time at various temperatures of 20,40 and $60^{\circ} \mathrm{C}$. Water separation increases at elevated temperature. This could be due to an increase of dispersed brine droplets collision at the elevated temperature which causes more coalescence and separation. In other words, raising temperature decreases film stability and elasticity around water droplets lowering viscosity of oil, increasing oil mobility and growing settling rate of water droplets. Consequently, interfacial film breaking and coalescence of water droplets will be easier at elevated temperatures. Figure 3 demonstrated that when temperature increases the settling time of demulsification decreases and also a $95 \%$ separation of water was observed in $30 \mathrm{~min}$.

\subsection{Effect of water content}

Figure 4 exhibited the effect of water content on demulsification efficiency at $60^{\circ} \mathrm{C}$. Generally, as water content of emulsion increases, WSI grows leading to an increase in demulsification efficiency. This increase of demulsification efficiency at higher water contents might be due to asphaltene content in the crude oil. As a result, the system tends to be unstable owing to the limited amount of asphaltenes that are adsorbed on the $\mathrm{W} / \mathrm{O}$ interface. When asphaltene adsorption decreases through increasing water content, separation of water becomes easier. In addition, increasing water content of an emulsion may result to form large droplets that can coalesce and collide to each other. Thus, at any specific time in this study, WSI for emulsion containing $50 \%$ water content was larger than the others. The effect of water content on demulsification efficiency of emulsions at $60^{\circ} \mathrm{C}$ is depicted

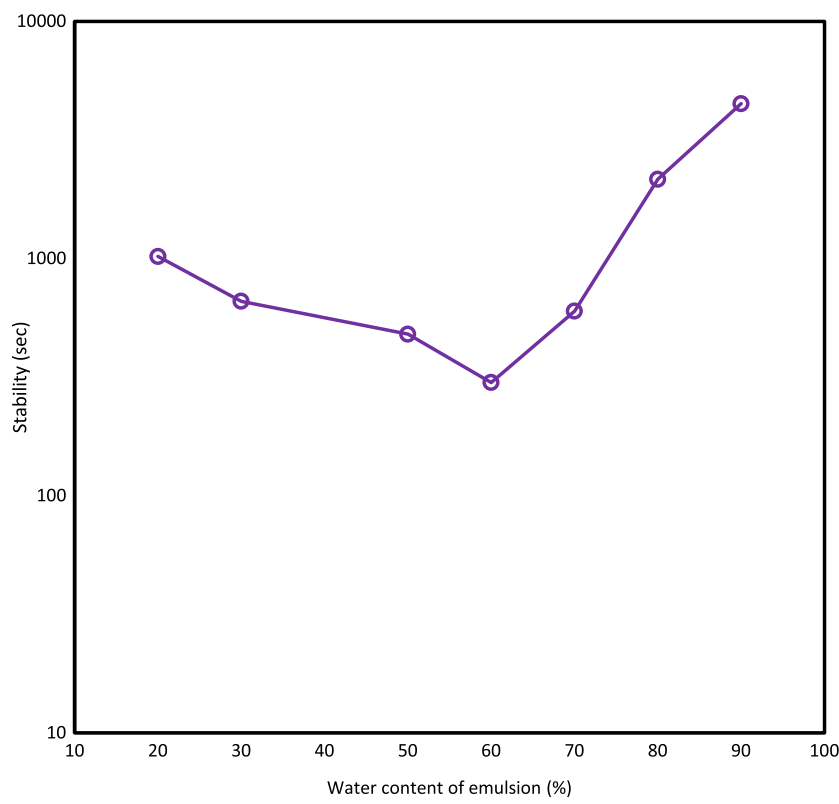

Fig. 5. Effect of water content on the stability of emulsion.

in Figure 5, in which $2 \mathrm{~mL}$ of demulsifier were added to $25 \mathrm{~mL}$ of emulsions. The emulsion stability is usually considered as the requisite time for separating a definite volume of water content of an emulsion. In this study, stability is the time required for separating of $50 \%$ of water content of the emulsion with an accuracy of $10 \mathrm{~s}$. As shown in Figure 5, minimum stability takes place in emulsion with $60 \%$ of water content. The minimum stability matches the emulsion inversion from $\mathrm{W} / \mathrm{O}$ to $\mathrm{O} / \mathrm{W}$ emulsion by increasing water content. This demulsifier is made to break w/o emulsions therefore they have a low performance in $\mathrm{o} / \mathrm{w}$ emulsions treating. In addition to a minimum stability point, Figure 5 states that for water contents of 20 and $90 \%$, very high emulsion stability was observed. In the other hand, when the volume of one phase significantly goes beyond the volume of another phase, the highest emulsion stability will occur which is not desirable.

\subsection{Effect of demulsifier dosage}

Effect of demulsifier dosage on demulsification efficiency of ADBSA in comparison with a Commercial Demulsifier (CD) is shown in Figure 6, in which different volumes of demulsifier were added to $30 \%$ of $25 \mathrm{~mL} \mathrm{w} / \mathrm{o}$ at the temperature of $60{ }^{\circ} \mathrm{C}$. Figure 6 shows that adding demulsifier up to certain level increases demulsification efficiency then by formation of a second layer it lowers water separation efficiency. ADBSA surfactant dosage that causes the highest separation is in a reasonable range ( 0.065-0.109 wt.\%). At lower dosage, addition of demulsifier increases their adsorption at the interface of dispersed droplets with oil; thus, the Separation of Water (WSI) increases or emulsion stability significantly decreases. The decrease in stability can be explained in such a way that even a small amount of demulsifier molecules contributing at interface can diminish the rigidity of the interfacial film. 


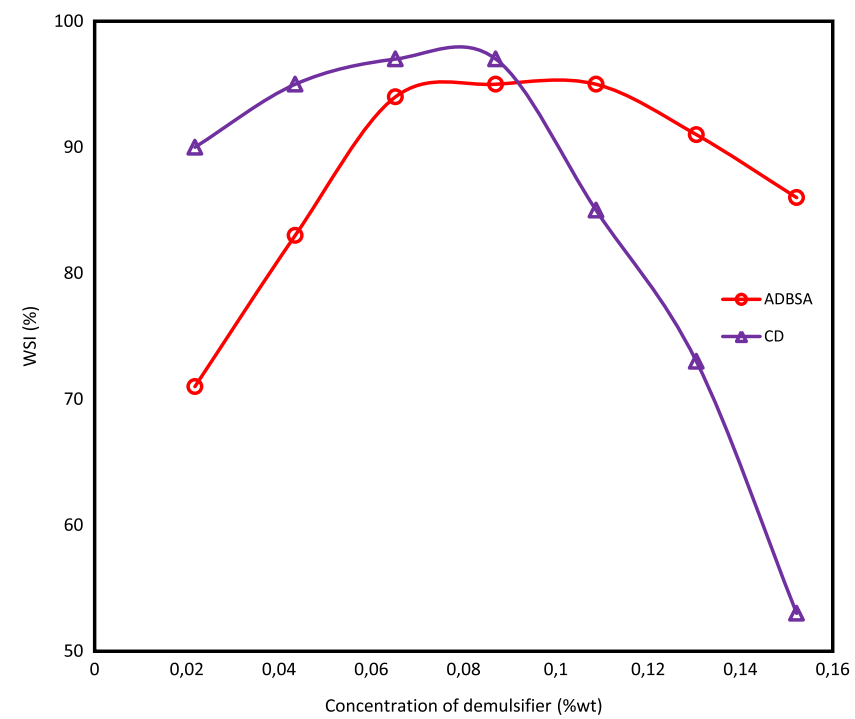

Fig. 6. Effect of demulsifier dosage on water separation index by comparing ADBSA and a Commercial Demulsifier (CD) potential.

Moreover, for higher demulsifier dosage than a certain value the efficiency decreases because of formation of a new demulsifier layer. Since the interface is already saturated by the surfactant micelles consequently the demulsifier dosage keeps approximately constant at the interface. In other words, this phenomenon results in bonding between other water droplets and oil film. As a result of increasing demulsifier dosage, the inversion of the emulsion may occur to reduce WSI. Another important point obtained from Figure 6 is the gradual increase of water separation before a certain value, and then the sharp decrease of water separation after this optimum value, which occurs in the approximate range of $0.065-0.087 \mathrm{wt} . \%$ As can be seen, the highest WSI for CD and ADBSA are 97\% and 95\%, respectively, which are approximately identical. It is noteworthy that the proposed demulsifier in this study is a single surfactant; however, the CD is a blend of several surfactant and compounds with a complex formula. It should be interesting to correlate the CMC value of the sulfanilic acid based surfactant demulsifier obtained in Section 3.1 (see Fig. 2) with the impact of demulsifier dosage in Section 4.5 (see Fig. 6). The comparison could lead to interesting interpretations. As shown in Figure 6, the region of acceptable separation can be achieved for demulsifier dosages much less than CMC value. In fact, the highest WSI occurs in concentration of $0.087 \mathrm{wt} . \%$ which is less than half of the CMC value (i.e., $0.225 \mathrm{wt} . \%$ ).

\subsection{Effect of brine salinity}

Figure 7 demonstrates that the emulsions stability of ADBSA surfactant versus salinity at $60^{\circ} \mathrm{C}$ using $30 \% \mathrm{w} / \mathrm{o}$ emulsions. In accordance to this figure, by increasing brine salinity, stability of the emulsion decreases. In the other hand, adsorption of surfactant at interface of emulsion increases due to an electrostatic attraction between

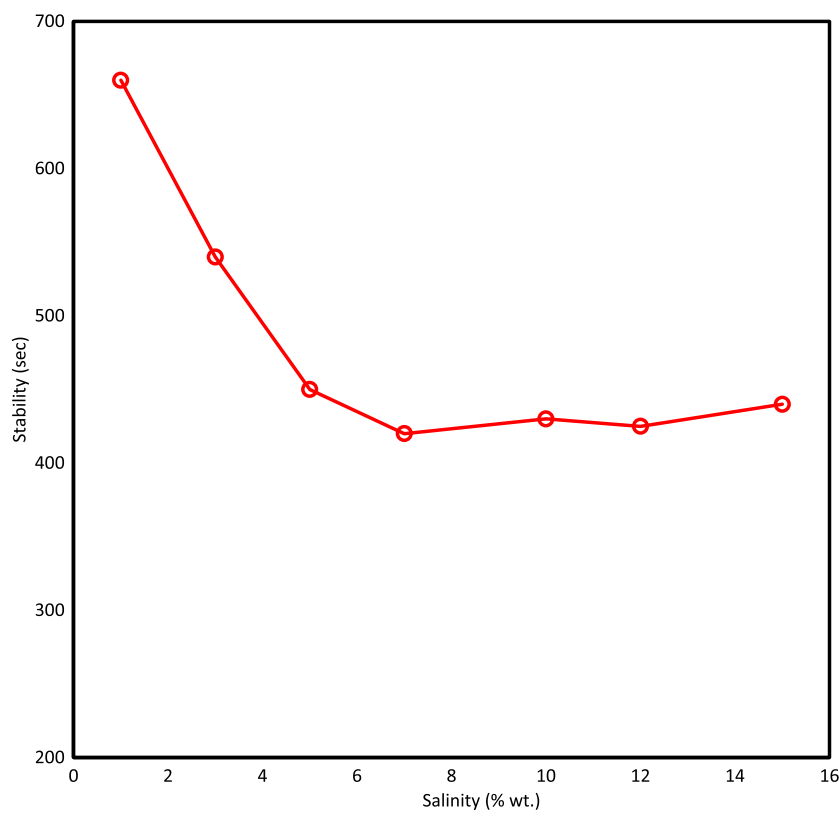

Fig. 7. Effect of brine salinity on emulsion stability of ADBSA.

Table 2. Properties of three crude oils labeled P1, P2 and P3.

\begin{tabular}{llll}
\hline & \multicolumn{3}{c}{ Oil property } \\
\cline { 2 - 4 } $\begin{array}{l}\text { Crude } \\
\text { oil }\end{array}$ & $\begin{array}{l}\text { API gravity } \\
\left({ }^{\circ} \mathrm{API}\right)\end{array}$ & $\begin{array}{l}\text { Viscosity at } \\
60^{\circ} \mathrm{C}(\mathrm{cP})\end{array}$ & $\begin{array}{l}\text { Asphaltenes } \\
(\text { wt.\%) }\end{array}$ \\
\hline P1 & 28.4 & 20.5 & 5.6 \\
P2 & 19.0 & 185.4 & 11.0 \\
P3 & 10.9 & 511.3 & 9.5 \\
\hline
\end{tabular}

surfactant molecules and $\mathrm{NaCl}$ ions. In fact, the main effect of the addition of salt is to decrease the repulsion between surfactant molecules due to electrostatic forces which allows an increase of the surfactant density at the $\mathrm{W} / \mathrm{O}$ droplets and therefore promote the emulsion destabilization.

This reduction leads to a specific salinity. This investigation reveals that a salinity of about $7 \%$ by weight enhances the demulsification efficiency. After that, increasing brine salinity does not have a substantial impact on demulsification efficiency or emulsion stability.

\subsection{Effect of different crude oils (Composition)}

To apply ASTM D6560-00 method, the asphaltene content of Asmari (P1), Binak (P2) and Azadegan (P3) oil samples were measured. In this section, the effect of different crude oil (crude oil composition) samples was investigated. Three different crude oils from Asmari (P1), Binak (P2) and Azadegan (P3) fields which have different composition and properties were studied. The properties of these crudes are given in Table 2. Based on this table, $\mathrm{P} 2$ and $\mathrm{P} 3$ are more asphaltenic and more viscous samples than the P1. By 


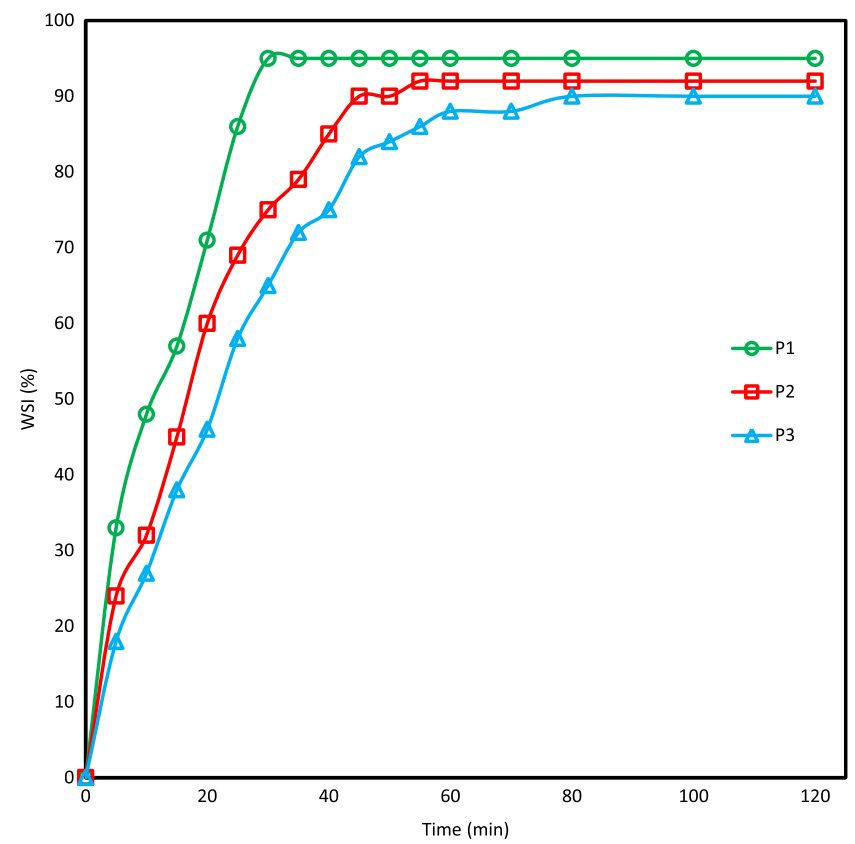

Fig. 8. Comparison of stability of different crude oil emulsions in presence of ADBSA.

knowing this fact, the demulsification experiments of these crude oil samples were conducted and compared with each other. Figure 8 illustrates the results of WSI versus time for ADBSA surfactant. Oil samples P1, P2 and P3, the amount of W/O emulsion, salinity, temperature and added volume of demulsifier were studied at $60^{\circ} \mathrm{C}$. Both asphaltene content and viscosity of crude oil affect the emulsion stability. As Figure 8 shows oil samples of P2 and P3 that were more viscous and more asphaltenic than $\mathrm{P} 1$, have made more stable emulsions. The final WSI was not very different but the settling time altered considerably. Settling time of P1, P2 and P3 were 30,55 and $80 \mathrm{~min}$, respectively. With increasing asphaltene content, the film rigidity increases, therefore emulsion becomes more stable. Moreover, movement, aggregation and coalescence of water droplets become more difficult by increasing oil viscosity.

\section{Conclusion}

In this study, bottle testing was conducted to investigate the efficiency of ADBSA surfactant as a demulsifier. Quantitative (settling time and WSI) and qualitative (presence of rag layer and quality of water) parameters were employed in our analysis. It is observed that ADBSA surfactant contains two powerful hydrophilic groups of ammonium and sulfonic ions, demonstrated excellent demulsification efficiency. Based on the obtained experimental results, the following conclusions are made:

- water separation increases at elevated temperature; in another word the stability of brine-crude oil emulsion decreases by increasing temperature;

- demulsification efficiency increases at higher water contents, this could be due to presence of limited amount of asphaltenes that are adsorbed on the $\mathrm{W} / \mathrm{O}$ interface;
- demulsification efficiency increases by adding demulsifier up to certain level, and;

- the absorption rate of ADBSA surfactant is increased at interface of emulsion by growing salinity due to an increase in electrostatic attraction between surfactant molecules and $\mathrm{NaCl}$ ions;

- the most stable emulsions were achieved when the volume of one phase significantly exceeds the volume of another phase.

Acknowledgments. We would like to acknowledge the research center of Petroleum University of Technology (PUT) for their financial support to this project.

\section{References}

1 Ahmed N.S., Nassar A.M., Zaki N.N., Gharieb H.K. (1999) Stability and rheology of heavy Crude oil-in-water emulsion stabilized by an anionic-nonionic surfactant mixture, Pet. Sci. Technol. 17, 553-576.

2 Aguilera B., Delgado J., Cardenas A. (2010) Water-in-Oil emulsions stabilized by asphaltenes obtained from venezuelan crude oils, J. Disp. Sci. Technol. 31, 359-363.

3 Al-Sabagh A.M., Kandile N.G., Noor El-Din M.R. (2011) Functions of demulsifiers in the petroleum industry, Sep. Sci. Technol. 46, 1144-1163.

4 Sjoblom J. (2001) Encyclopedic Handbook of Emulsion Technology, CRC Press, Taylor and Francis, Florida, United States.

5 Ali M., Chhetri A., Ketata C., Islam M. (2009) Microscopic study of oil flocculation and coalescence processes for understanding the role of surfactants in EOR performance, Pet. Sci. Technol. 27, 1251-1260.

6 Fan Y., Simon S., Sjoblom J. (2009) Chemical destabilization of crude oil emulsions: effect of nonionic surfactants as emulsion inhibitors, Energy Fuels 23, 4575-4583.

7 Sadeghi M.B., Ramazani S.A., Taghikhani V., Ghotbi C. (2013) Experimental investigation of rheological and morphological properties of water in crude oil emulsions stabilized by a lipophilic surfactant, J. Disp. Sci. Technol. 34, 356-368.

8 Nikkhah M., Tohidian T., Rahimpour M.R., Jahanmiri A. (2015) Efficient demulsification of water-in-oil emulsion by a novel nano-titania modified chemical demulsifier, Chem. Eng. Res. Des. 94, 164-172.

9 Al-Sabagh A., Noor El-Din M., Abo-El Fotouh S., Nasser N. (2009) Investigation of the demulsification efficiency of some ethoxylated polyalkylphenol formaldehydes based on locally obtained materials to resolve water-in-oil emulsions, J. Disp. Sci. Technol. 30, 267-276.

10 Wang S., Zhao J., Li X., Yang S., Wang X., LiuY., Yang S., Dong Q. (2017) Numerical simulations on effects of ionic/nonionic surfactant on oil-water interface using dissipative particle dynamics, Asia-Pac. J. Chem. Eng. 12, 268-282.

11 Wang J., Li C.-Q., An N., Yang Y. (2012) Synthesis and demulsification of two lower generation hyperbranched polyether surfactants, Sep. Sci. Technol. 47, 1583-1589.

12 Al-Sabagh A.M., Kandile N.G., El-Ghazawy R.A., El-Din M. R.N. (2011) Synthesis and evaluation of some new demulsifiers based on bisphenols for treating water-in-crude oil emulsions, Egypt. J. Pet. 20, 67-77. 
13 Fukumoto A., Dalmazzone C., Frot D., Barré L., Noïk C. (2018) Characterization of complex crude oil microemulsionsDSC contribution, Oil Gas Sci. Technol. - Rev. IFP Energies nouvelles $\mathbf{7 3}, 3$.

14 Karambeigi M.S., Haghighi Asl A., Nasiri M. (2018) MultiObjective optimization of microemulsion flooding for chemical enhanced oil recovery, Oil Gas Sci. Technol. - Rev. IFP Energies nouvelles, $\mathbf{7 3}, 4$.

15 Ghosn R., Mihelic F., Hochepied J.-F., Dalmazzone D. (2017) Silica nanoparticles for the stabilization of $\mathrm{W} / \mathrm{O}$ emulsions at HTHP conditions for unconventional reserves drilling operations, Oil Gas Sci. Technol. - Rev. IFP Energies nouvelles $\mathbf{7 2}, 21$.

16 Mezdour S., Séguineau de Préval E., Granda P., Cuvelier G., Ducept F. (2017) Impact of interfacial characteristics on foam structure: Study on model fluids and at pilot scale, Oil Gas Sci. Technol. - Rev. IFP Energies nouvelles 72, 13.

17 Daniel-David D., Le Follotec A., Pezron I., Dalmazzone C., Noik C., Barre L., Komunjer L. (2008) Destabilisation of water-in-crude oil emulsions by silicone copolymer demulsifiers, Oil Gas Sci. Technol. - Rev. IFP Energies nouvelles 63, 165-173.

18 Langevin D., Poteau S., Hénaut I., Argillier J. (2004) Crude oil emulsion properties and their application to heavy oil transportation, Oil Gas Sci. Technol. - Rev. IFP Energies nouvelles 59, 511-521.

19 Yang X., Tan W., Bu Y. (2008) Demulsification of asphaltenes and resins stabilized emulsions via the freeze/ thaw method, Energy Fuels 23, 481-486.

20 Guoxiang Y., Xiaoping L., Fei P., Pingfang H., Xuan S. (2008) Pretreatment of crude oil by ultrasonic-electric united desalting and dewatering, Chin. J. Chem. Eng. 16, 564-569.

21 Fang C., Chang B.K., Lai P.M., Klaila W. (1988) Microwave demulsification, Chem. Eng. Commun. 73, 227-239.
22 Xia L., Lu S., Cao G. (2004) Stability and demulsification of emulsions stabilized by asphaltenes or resins, J. Colloid Interface Sci. 271, 504-506.

23 Fortuny M., Oliveira C.B., Melo R.L., Nele M., Coutinho R. C., Santos A.F. (2007) Effect of salinity, temperature, water content, and $\mathrm{pH}$ on the microwave demulsification of crude oil emulsions, Energy Fuels 21, 1358-1364.

24 Tan W., Yang X.G., Tan X.F. (2007) Study on demulsification of crude oil emulsions by microwave chemical method, Sep. Sci.Technol. 42, 1367-1377.

25 Berdin Y.S., Krasnenko A. (1993) Modernization of centrifuges for separation of crude oil sludge, Chem. Technol. Fuels Oils 29, 157-159.

26 Bhardwaj A., Hartland S. (1994) Dynamics of emulsification and demulsification of water in crude oil emulsions, Ind. Eng. Chem. Res. 33, 1271-1279.

27 Ichikawa T. (2007) Electrical demulsification of oil-in-water emulsion, Colloids Surf. A: Physicochem. Eng. Asp. 302, $581-586$.

28 Schramm L.L. (2000) Surfactants: Fundamentals and Applications in the Petroleum Industry, Cambridge University Press, Cambridge, England.

29 Wang J., Li C.Q., Li J., Yang J.Z. (2007) Demulsification of crude oil emulsion using polyamidoamine dendrimers, Sep. Sci. Technol. 42, 2111-2120.

30 Takassi M.A., Ghol G.R., Zadehnazari A., Zargar G. (2016) A novel synthetic method and potential application of a sulfanilic acid-based surfactant, J. Disp. Sci. Technol. 37, 393-397.

31 Wong S., Lim J., Dol S. (2015) Crude oil emulsion: A review on formation, classification and stability of water-in-oil emulsions, J. Pet. Sci. Eng. 135, 498-504.

32 Al-Yaari M., Hussein I., Al-Sarkhi A., Abbad M., Chang F. (2015) Effect of water salinity on surfactant-stabilized wateroil emulsions flow characteristics, Exp. Therm. Fluid Sci. 64, 54-61. 